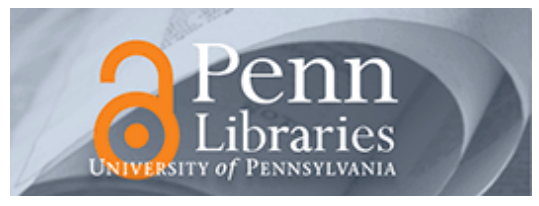

University of Pennsylvania

ScholarlyCommons

Management Papers

Wharton Faculty Research

$5-1-2008$

\title{
Contextuality Within Activity Systems and Sustainability of Competitive Advantage
}

Michael Porter

Harvard University

Nicolaj Siggelkow

University of Pennsylvania

Follow this and additional works at: https://repository.upenn.edu/mgmt_papers

Part of the Management Sciences and Quantitative Methods Commons

\section{Recommended Citation}

Porter, M., \& Siggelkow, N. (2008). Contextuality Within Activity Systems and Sustainability of Competitive Advantage. Academy of Management Perspectives, 22 (2), 34-56. http://dx.doi.org/10.5465/

AMP.2008.32739758

This paper is posted at ScholarlyCommons. https://repository.upenn.edu/mgmt_papers/302

For more information, please contact repository@pobox.upenn.edu. 


\title{
Contextuality Within Activity Systems and Sustainability of Competitive Advantage
}

\author{
Abstract \\ Research on the interactions among activities in firms and the extent to which these interactions help \\ create and sustain competitive advantage has rapidly expanded in recent years. In this research, the two \\ most common approaches have been the complementarity framework, as developed by Milgrom and \\ Roberts (1990), and the NK-model (Kaufman, 1993) for simulation studies. This paper provides an \\ introduction to these approaches, summarizes key results, and points to an aspect of interactions that \\ has not found much attention because neither of the two approaches is well-suited to address it: \\ contextual interactions, i.e., interactions that are influenced by other activity choices made by a firm. We \\ provide a number of examples of contextual interactions drawn from in-depth studies of individual firms \\ and outline suggestions for future research.

\section{Keywords} \\ Competitive advantage, contextualism, interaction, strategic planning, performance, simulation methods

\section{Disciplines} \\ Management Sciences and Quantitative Methods
}




\title{
Contextuality within Activity Systems
}

\author{
Michael E. Porter \\ Aldrich 200 \\ Harvard Business School \\ Boston, MA 02163 \\ tel: (617) 4956309 \\ fax: (617) 5478543 \\ mporter@hbs.edu \\ Nicolaj Siggelkow \\ 2017 SH-DH \\ Wharton School \\ University of Pennsylvania \\ Philadelphia, PA 19104 \\ tel: (215) 5737137 \\ fax: (215) 898-0401 \\ siggelkow@wharton.upenn.edu
}

February 20, 2001

We would like to thank Jan Rivkin for helpful discussions. Financial support by Harvard Business School and the Reginald H. Jones Center for Management Strategy, Policy and Organization is gratefully acknowledged. 


\title{
Contextuality within Activity Systems
}

\author{
Abstract: To further our understanding of creating and sustaining firm competitive advantage, \\ we need to recognize two types of contextuality within firms' activity systems. First, the benefit \\ of activity configurations can be contextual-while some activity configurations are generically \\ beneficial, others gain their value only as part of particular strategies. Second, interactions \\ among activities can be contextual. While some interactions between activities are an inherent \\ property of the activities themselves, other interactions are determined contextually by other \\ activity choices made by a firm. We argue that competitive advantage is likely to be more \\ sustainable if it is based on activities that are strategy-specific and that have contextual \\ interactions with other activities.
}

Short title: Contextuality within Activity Systems

Keywords: complementarities, fit, competitive advantage, competitive strategy, interaction effects, activity systems 


\section{Introduction}

The concepts of fit and complementarity among a firm's activities have recently received a good deal of attention. In particular, recent work in economics has focused on the adoption patterns of sets of activities that are best practices, or generally beneficial, and on analyzing sets of activities that are complementary for all firms. Hence, the emphasis has been on industrywide or cross-industry phenomena rather than on those specific to an individual firm. While the notion of "fit" among a firm's activities has a long-standing tradition in the field of management (e.g. Learned, et al., 1961), interactions among activities have not featured prominently in the recent strategy literature. In this paper, we connect the role of interaction among activities with perhaps the central question in competition: how to create and sustain a competitive advantagea question largely not addressed by recent work.

To understand firm-level competitive advantage, one must recognize two types of

contextuality within a firm's system of activities. ${ }^{1}$ First, the benefit of a particular configuration of an activity can be contextual. While some activities have configurations that are generically beneficial for all firms within an industry, the value of many activity configurations depends on the particular strategy a firm is pursuing. (Note, we use the term "activity configuration" to mean "a way to perform an individual activity," rather than "a set of coherent activities," a meaning previously attached to this term in the literature (e.g., Miller, 1986).) Second, the interactions among activities can be contextual. Complementarity is only a special, albeit important, case of the more general phenomenon of interaction among a firm's activities. In examining the role of interactions in creating and sustaining a competitive advantage, the existing literature on complementarities is limiting in three ways. First, the conditions for complementarity in the existing literature are very restrictive. Second, activities can interact as substitutes as well as complements. Third, the nature of the interaction between activities is 
contextual, i.e., determined by other activity choices made by the firm, rather than an inherent property of the activities themselves as has been assumed.

Both types of contextuality have important strategic consequences. Specifically, sustainable competitive advantage is more likely created by sets of strategy-specific activities that interact contextually than by sets of generic activities that interact in generic ways.

This paper is organized as follows: Section II contains an overview of the recent literature on fit and complementarity. In Section III, we outline the distinction between generic activities and strategy-specific activities. Section IV shows that different strategic positionings involving different sets of strategy-specific activities are often present within industries. Section V discusses the contextuality of interactions among activities and introduces a typology that combines the distinction between generic and strategy-specific activities with the distinction between generic and contextual interactions. Section VI illustrates different forms of contextuality with examples drawn from detailed firm- and industry-level analyses. Section VII discusses the competitive consequences of contextual interactions. Section VIII outlines implications of contextuality for large-sample empirical research. Section IX concludes.

\section{The concepts of complementarity and fit in the recent literature}

Neo-classical economic analysis has traditionally employed a rigorous, yet simple view of competition. Firms are modeled to compete on one variable (price or quantity) or to engage in two-stage competitions with, for instance, a capacity or advertising choice in the first stage and a price or quantity choice in the second stage (for an overview see Tirole, 1988). In contrast, the strategy literature has traditionally conceptualized competition as taking place in a higherdimensional space. Firms compete on a whole range of attributes with products and services geared towards particular segments or subsets of the market. Moreover, firms create and deliver their products and services through a complex array of activities. Consequently, in the strategy 
literature, the "firm" emerges as a much richer, if less rigorously modeled, entity that has to engage in a wide array of choices with respect to product line, target markets, marketing, sales, distribution, manufacturing, human resources, purchasing, research and development, and finance and control. Moreover, it is a long-held view in the strategy field that these choices have to be consistent, or fit together (Chandler, 1962; Drazin and Van de Ven, 1985; Hambrick, 1984; Khandwalla, 1973; Learned, et al., 1961; Miller, 1981; 1986; Miller and Friesen, 1978; 1984; Mintzberg, 1979).

Previous work on fit in the management literature has been mainly concerned with consistency at a broad functional level (e.g., between distribution and manufacturing). Recent management literature, conceptualizing firms as a series of discrete but interdependent activities in which competitive advantage resides (Porter, 1985), has adopted a more fine-grained level of inquiry focusing on fit at the level of individual activities. For instance, a number of studies conducted at the activity level explained the Japanese approach to manufacturing (Jaikumar, 1989; MacDuffie and Krafcik, 1992; Nemetz and Fry, 1988; Parthasarthy and Sethi, 1992).

The shift from mass production to lean manufacturing also attracted the attention of economists to the ways in which company activities interact. For instance, Milgrom and Roberts (1990a; 1995) describe the characteristic features of the mass production and lean manufacturing systems and propose an optimizing model of the firm that generates many of the observed patterns in the transition from one system to the other. In particular, Milgrom and Roberts' model accounts for the observation that a successful transformation from one system to the other requires a substantial change in a wide range of a firm's activities.

Two key insights form the basis of Milgrom and Roberts' work, one conceptual, one mathematical. First, they observe that many activities within a given production system are complementary to each other. Two activities are defined to be complementary if the marginal benefit of one activity is increased by the level of the other activity. Second, they develop 
lattice-theoretic methods building on the work of Topkis (1978) that allow an exact formulation of the notion of complementarities involving a large set of choices. With these methods, models with an unusually large number of variables and relatively weak assumptions (by economic standards) are amenable to tractable analysis. (We will return to the assumptions in Section V.)

Milgrom and Roberts' model has spurred both theoretical and empirical research. A growing literature has continued to develop and apply the mathematical apparatus in a wide variety of formal models, for instance, addressing issues such as investments in product and process flexibility and optimal partitioning of design problems (Athey and Schmutzler, 1995; Bagwell and Ramey, 1994; Holmström and Milgrom, 1994; Milgrom, Qian and Roberts, 1991; Milgrom and Roberts, 1990b; 1996; Milgrom, Roberts and Athey, 1996; Milgrom and Shannon, 1994; Prat, 1996; Schaefer, 1999).

Empirical work in this line of research has pursued mainly two directions: a) finding support for complementarity among various activities by studying the performance implications of engaging in individual activities versus entire sets of activities, and b) inferring complementarities by studying adoption patterns of new technologies and practices. (For a thorough exposition of the inherent econometric problems involved in identifying complementarities, see Athey and Stern (1998).)

A notable example of the first type of empirical study is Ichniowski, Shaw, and Prennushi (1997), who study the effect of adopting individual human resource management (HRM) practices versus entire sets of HRM practices on the productivity of steel finishing lines. They find "consistent support for the conclusion that groups or clusters of complementary HRM practices have large effects on productivity, while changes in individual work practices have little or no effect on productivity" (p. 291). Ichniowski and Shaw (1999) report a similar finding using an expanded sample including both U.S. and Japanese steel finishing lines. Likewise, MacDuffie and Krafcik (1992) find for firms in the U.S. automobile industry a synergistic payoff 
between the adoption of "lean" production processes and a set of HRM practices, including shop floor work organization and incentive clauses in employment contracts. MacDuffie (1995) extends this work to a larger set of automobile assembly plants located worldwide, finding a complementary relationship between team-based work systems, high-commitment HRM practices, and low inventory and repair buffers. Similarly, Parthasarthy and Sethi (1993), studying firms in the U.S. automotive, aerospace, light/heavy machinery, and consumer electronic industries, show that benefits to flexible automation are positively increased by skill diversity and team approaches to manufacturing. Brown, Reich, and Stern (1993) study five U.S. firms that sought to adopt new employment systems characterized by flexible job assignments, employee involvement in problem solving, and continuous training for workers. They find that moving to the new practices failed when the practices were implemented in a gradual and partial manner. Cockburn, Henderson, and Stern (1999) show in a sample of large pharmaceutical firms that a complementary relationship exists between the degree to which publications in scientific journals are important for career advancement and intensity of incentives to conduct applied research.

Research exploring complementarity of activities outside the human resource arena includes Clark and Hammond (1995) who study the U.S. grocery industry. They show that the benefits of establishing EDI linkages between retailers and suppliers in conjunction with the adoption of vendor-managed inventory programs (VMI) is larger than the sum of the benefits of adopting EDI and VMI alone. Hwang and Weil (1998), studying the U.S. apparel supply channel, find complementarities among practices such as bar coding, order processing using EDI, shipping labels for easier sorting, and team production.

On a broader organizational level, Whittington et al. (1999) study the performance implications of ten distinct changes in organizational structures, processes and firm boundaries using a survey of 383 European firms. Consistent with complementarities, they find that 
piecemeal changes (with the exception of investments in information technology) deliver little performance benefit, while exploitation of the full set of innovations is associated with high performance. In particular, a positive performance effect arises only if changes to structures, processes, and firm boundaries are combined. No performance effect, or even a negative effect, is found when changes address only two of these areas.

Empirical studies in the second stream of literature on adoption patterns of new practices and technologies, include Colombo and Mosconi (1995), who investigate the adoption patterns of flexible manufacturing systems, new design/engineering technologies, and new management techniques such as JIT and total quality procedures in the Italian metalworking industry. They observe that all of these innovations tend to be adopted together, providing an indication of complementarity among them. Hitt and Brynjolfsson (1997), in a study of 273 firms from the Fortune 1000 list, find that firms that are extensive users of information technology tend to adopt a complementary set of organizational practices that include decentralization of decision authority, emphasis on subjective incentives, and a greater reliance on skills and human capital. Other studies concerned with adoption patterns include Antonelli, Petit, and Tahar (1990) who study the diffusion of interdependent innovations in the Italian textile industry, and Abernathy, Dunlop, Hammond, and Weil (1995) who study the diffusion of new practices in the U.S. textile supply chain linking apparel manufacturers to distributors and retailers, such as EDI and automated distribution operations.

\section{Generic versus strategy-specific activities}

Since Milgrom and Roberts' seminal article (1990) focused on the shift from massproduction to lean-production, it is perhaps not surprising that almost all existing studies focus on industry-wide or even broader phenomena. The studies explore activity configurations that are beneficial for many firms and activities that are complementary in the same manner for all 
firms within an industry or broader. (Henceforth, we will use the phrase "within an industry" to refer to both.)

While these are important situations to study, they represent only a subset of the ways in which activity choices and interactions among activities can affect competition. In particular, an explanation for sustainable competitive advantage, i.e., for long-term superior profitability, is unlikely to be found in such cases. If a particular activity configuration is beneficial for all firms within a given industry, then this configuration is unlikely to be a source of sustained competitive advantage because competitors are likely to adopt this configuration sooner or later. Similarly, if the interactions among a particular set of activities is common across firms, this set of activities is likely to be more easily imitated by competitors (as argued below), thus rendering competitive advantage less sustainable.

In this section, we will focus on the distinction between activities for which configurations exist that are beneficial for all firms (e.g., best practices) and activities for which the configurations' benefits depend on the particular strategy a firm is following. In Section V, we will distinguish between different types of interactions among activities.

We define an activity for which a configuration exists that is optimal for all firms within an industry as a generic activity. Generic activities are not unimportant-quite to the contrary. They set the bar for competition. A firm that does not attain parity on such activities is at a competitive disadvantage. Yet, at the same time, other firms also have the incentive to pursue the same improvements delivered by these generic activities, or universal best practices.

Competitive advantage is more likely to arise from activities that have more than one optimal configuration, i.e., from strategy-specific activities. These activities are thus tailored to a firm's particular strategy. Particular configurations of such activities are more beneficial to one firm than they are to its rivals, i.e., the benefit of these activity configurations is contextual. 
The distinction between improving generic activities - in the terminology of Porter (1996), increasing operational effectiveness - and strengthening strategy-specific activities (activities tailored to a particular strategic positioning) is crucial since the latter require strategic choices. Given the focus of the recent literature on generic activities, the impression is frequently left that firms should compete using the same set of "optimally" configured activities. While the pursuit of the same set of generic activities may increase efficiency, profitability is often not improved (Cusumano, 1994; Stalk and Webber, 1993).

In most industries, a number of different and profitable positionings (implemented by different activity sets) are present. Thus, firms need not race towards one "ideal" set of "optimally" configured activity choices, but can pursue different strategies which can lead to sustained competitive advantage.

In the terminology of performance landscapes ${ }^{2}$ (Kauffman, 1993; Levinthal, 1997; Rivkin, 2000), generic activities correspond to "mesas." All firms should locate in these areas and seek peaks that stand out from the high plateaus. In the case with two choices (the most complicated we can easily draw in three dimensions), a mesa correspond to a "ridge." Figure 1 depicts this case. Regardless of the level of Activity 1, the highest performance is achieved for a medium level of Activity 2. Thus, a medium level of Activity 2 is the optimal configuration (a best practice) for all firms, i.e., Activity 2 is a generic activity. This does not imply, however, that there is no room for strategic positioning. In the case depicted in Figure 1, two equally valuable strategic positionings exist: combined with a medium level of Activity 2, peaks exist at very low and very high levels of Activity 1.

$<$ FIGURE 1 ABOUT HERE $>$ 


\section{The existence of multiple strategic positions}

The existence of strategy-specific activities implies that industries allow for multiple strategic positions. In previous research, this idea has found expression in the work on strategic groups (Caves and Porter, 1977; Cool and Schendel, 1987; 1988; Cool and Dierickx, 1993; Fiegenbaum and Thomas, 1995; Hatten and Schendel, 1977; Hatten and Hatten, 1987; McGee and Thomas, 1986; Oster, 1982; Porter, 1976; 1979; Thomas and Venkatraman, 1988).

Data constraints frequently made it necessary to group firms on the basis of very broad indicators of activity choices and hence strategic positionings, such as the level of advertising, $R \& D$ intensity, number of items in the product line, etc. With a finer-grained analysis that addresses strategy-specific choices at the activity level and the interactions among them, this literature could be usefully extended to show the different positionings that firms have chosen within an industry. Similarly, analyzing firms and their resulting positionings at the activity level provides greater richness to the related concept of "mobility barriers" (Caves and Porter, 1977; Caves and Ghemawat, 1992). Once a firm's strategy-specific activities and the interactions among them have been revealed, it is often possible to understand why firms that try to move from their old position to a new position, or try to straddle them both, encounter severe difficulties (Porter, 1996; Siggelkow, forthcoming).

We offer three short examples of how different sets of activity configurations can lead to different strategic positionings within an industry. In the wine industry, Robert Mondavi and E. \& J. Gallo compete successfully with very different systems of activities. Mondavi, the leading premium wine producer, produces high quality wine employing premium grapes, many grown in its own vineyards. Grapes sourced from outside growers are purchased under long-term contracts from suppliers with whom the company has deep relationships, sharing knowledge and technology extensively. Grapes are handled with great care in Mondavi's sophisticated production process, which involves extensive use of hand methods and batch technologies to 
ensure the highest quality. Wine is fermented in redwood casks and extensively aged in small oak barrels. Mondavi makes heavy use of wine tastings, public relations, and wine tours in marketing relative to media advertising. Gallo, in contrast, produces large volumes of popularly priced wine using highly automated production methods. The company purchases the majority of its grapes from outside growers and is also a major importer of bulk wine for use in blending. Gallo's production facilities look more like oil refineries than wineries. Bulk aging takes place in stainless steel tank farms. Gallo spends heavily on media advertising and is the leading advertiser among California wineries. These two very different systems of activities reflect Mondavi and Gallo's different positionings.

Home improvement retailing provides another example of two competitors who have prospered over the last decade through different systems of activities. Home Depot and Lowe's have different strategies, which are reflected in many different activity configurations. Home Depot offers the widest selection of items in huge stores that average over 130,000 square feet. The store design, involving no frills and very high ceilings, allows large quantities of merchandise to be inventoried on store shelves. Home Depot has no warehouses or distribution centers, but stores receive direct deliveries 24 hours per day from a strictly limited number of vendors. Goods unloaded from vendor trucks are placed directly onto the selling floor using palettes. Home Depot employs well-trained employees, many of whom are former trades people, to provide customer service. The company appeals especially to "do-it-yourselfers," many of whom are men, as well as smaller contractors. Both are attracted to Home Depot's low prices.

Lowe's, while offering much of the same merchandise, places greater emphasis on fashion, kitchen, lawn and garden, and decorating items. Instead of displaying piles of merchandise on palettes and racks, Lowe's features store-within-a-store displays of kitchens, window treatments, and other items as they appear in the home. Lowe's stores have lower ceilings, brighter lighting and more attractive shelving. As a result, they must be restocked more frequently and in smaller 
quantities. To do this, Lowe's maintains regional distribution centers which are sited relative to stores using the hub and spoke principle and designed to support regular store replenishment mostly after hours. Lowe's is price competitive with Home Depot on common items, but has a higher proportion of unique and fashion items that command higher margins. The company appeals disproportionately to women, who are often the decision makers on more fashion and decorating items. Contractors are served by a separate corporate division from separate and different facilities.

A third example of differing positions within the same industry can be found in the automobile insurance industry. There are two broad types of insurance providers: those serving standard (low-risk) drivers, such as State Farm, and providers serving non-standard (high-risk) drivers, such as Progressive Corporation. As a consequence of their different target customers, these companies have pursued two different systems of activity configurations. Here, we highlight a subset of the firms' activity systems, the settlement of claims. The activity design followed by most standard insurers is to investigate and settle claims deliberately in order to hold down costs and earn further returns on the invested premium. Most standard auto insurers register operating losses in their insurance business, i.e., claims and operating expenses exceed premiums, and profitability depends on the returns earned on the float before claims are settled.

A different set of activity configurations, put into practice by Progressive, is to pay as quickly as possible. Progressive makes personal contact with over $75 \%$ of claimants within 24 hours and settles over 55\% of all claims within 7 days. In many cases, a Progressive adjuster will come to the accident scene and issue a check on the spot. The rationale behind this choice is to reduce the number of lawsuits which tend to escalate costs but do not ultimately benefit the insured. ${ }^{3}$ Many other activities influence the time between an accident and the final issuing of a check. Activity configurations that lead to quicker responses include: education of the customer to call an 1-800 number right after an accident; staffing such telephone support system; 
equipping adjusters with vans and having them on call around the clock; extensive training of adjusters and allowing them to write a check on the scene; contacting policy holders very quickly after accidents; and improving back-office processes that allow rapid settlement. While both approaches to claims settlement represent coherent sets of activity configurations, the profitability of each approach depends on the type of customers served. For Progressive, which concentrates on non-standard customers who are more likely to be involved in an accident and who generally choose only the smallest coverage levels required by law, a fast settlement process is optimal because the margin for error by adjusters is limited. Moreover, facing less competition to insure high-risk drivers, Progressive can earn operating income on the underwriting and is thus less dependent on the float to become profitable. In contrast, for standard insurers, whose customers choose much larger coverages, this response approach tends not to be optimal.

\section{Contextual interactions}

In addition to different choices for how to perform discrete activities, there are different types of interactions among activities. In particular, we differentiate between sets of activities that interact in similar ways in all firms and sets of activities whose interactions are contextual. A useful starting point for discussing contextual interactions is Milgrom and Roberts' (1990) definition of complementarity (for more details see the Appendix):

Let $f(x, y, z)$ be a (benefit) function where $z$ is a vector of variables. The variables $x$ and $y$ are complements if $f$ has the following property:

$$
\begin{aligned}
& f\left(x^{\prime}, y^{\prime}, \boldsymbol{z}\right)-f\left(x^{\prime}, y^{\prime \prime}, \boldsymbol{z}\right)>f\left(x^{\prime}, y^{\prime}, \boldsymbol{z}\right)-f\left(x^{\prime}, y^{\prime}, \boldsymbol{z}\right) \\
& \quad \text { for all } x^{\prime \prime}>x^{\prime}, y^{\prime \prime}>y^{\prime} \\
& \quad \text { and all values of } \boldsymbol{z}
\end{aligned}
$$


In words, increasing the variable $x$ from its lower level $x$ ' to the higher level $x$ " is more beneficial when the second variable $y$ is at the higher level $y$ ' than at the lower level $y$ '. Condition (1b) states that this relationship between $x$ and $y$ has to hold for all levels of $x$ and $y$. Condition (1c) requires that this relationship hold for all values of all the other variables $z$. Only if the above conditions hold for all pairs of variables (between $x, y$, and $z$ and among the variables constituting $\boldsymbol{z}$ ), does the set of variables $\{x, y, z\}$ form a system of complements.

Translated into the activity terminology, each variable corresponds to an activity, while $x$, $x$ ”, etc. are different configurations of activity $x$. Note that Milgrom and Robert's complementarity framework requires that the possible choices for each activity can be ordered (e.g., small vs. large investments in flexible machinery). All statements of activity "levels" are thus to be understood with respect to such an order.

The above definition of a system of complements is convenient because it yields robust comparative statics properties: any (exogenous) decrease in the marginal cost of any element in the system of complements will (weakly) increase the optimal level of all elements in the system (for more details see the Appendix). The above formulation also holds mathematical interest because the relationships (1a)-(1c) describe the weakest sufficient conditions on $f$ to yield these comparative statics result (Milgrom, Roberts and Athey, 1996).

This framework has made it possible to devise robust models that include a large number of variables, and it has been successfully employed to explain a number of important phenomena, e.g., the shift from mass- to lean manufacturing. The framework has also guided empirical research on broad adoption patterns for new practices and promises to yield further important insights. However, for the central question of strategy — how firms can achieve above-average performance - the restrictive definition of complementarities is less satisfying for three reasons.

First, the interactions among activities rarely hold for all levels of these activities, i.e., condition (1b) may be violated. Two activities might be complementary over a range of their 
values, but not complementary outside the range. Second, interactions among activities are frequently not as independent of other activity choices as the above definition of complementarities requires. In other words, condition (1c) is violated. Third, complementarity is but one case of how activities interact. Activities within firms can interact as substitutes as well. ${ }^{4}$ For instance, as a firm increases its investment in quality control leading to fewer defects in its products, the marginal benefits of increasing after-sale service support dealing with faulty products is likely to decrease.

To gain a richer understanding of the role played by activity interactions in creating a competitive advantage, we need to distinguish between interactions among activities that are context-free, i.e., for which conditions (1b) and (1c) hold, and interactions among activities that are contextually affected. If the interaction between two activities A and B satisfies conditions (1b) and (1c), the interaction between these activities is similar in all firms, because the interaction does not depend on how A and B are embedded within the activity system of the firm. Consequently, we call such interactions generic. However, if the interaction between A and B is, for instance, influenced by a third activity choice $\mathrm{C}$, we call this interaction contextual.

A simple example can illustrate the concept of contextuality while revealing the restrictiveness of the complementarity conditions. Consider the case of three activities A, B and C. Each activity can be configured in two ways, which we denote by 0 and 1 . Hence, the firm can consider eight possible combinations of ABC: 000, 001, ., 111. We normalize the payoff of the combination 000 to be zero. Figure 2 displays a case in which $\mathrm{A}, \mathrm{B}$ and $\mathrm{C}$ are complements. In this case, changing one and only one activity from 0 to 1 yields a benefit of one, changing two activities yields a benefit of three, and changing all three activities yields a benefit of six. Thus, the payoffs of the eight combinations are given as follows: $\Pi(000)=0$; $\Pi(100)=\Pi(010)=\Pi(001)=1 ; \Pi(110)=\Pi(101)=\Pi(011)=3 ; \Pi(111)=6$. To check the complementarity between $\mathrm{A}$ and $\mathrm{B}$, for instance, note that changing $\mathrm{A}$ from 0 to 1 is more 
beneficial if $\mathrm{B}$ is at its higher level 1 rather than at 0 . Similarly, changing B from 0 to 1 is more beneficial if $\mathrm{A}$ is at its higher level of 1 rather than at 0 . Moreover, note that these relationships hold regardless of the level of $\mathrm{C}$. Thus, the interaction between $\mathrm{A}$ and $\mathrm{B}$ is generic:

for $\mathrm{C}=0$ :

A's marginal benefit is larger at the higher level of B:

$$
2=\Pi(110)-\Pi(010)>\Pi(100)-\Pi(000)=1
$$

B's marginal benefit is larger at the higher level of A:

$$
2=\Pi(110)-\Pi(100)>\Pi(010)-\Pi(000)=1
$$

Similarly for $\mathrm{C}=1: \quad 3=\Pi(111)-\Pi(011)>\Pi(101)-\Pi(001)=2$

$$
3=\Pi(111)-\Pi(101)>\Pi(011)-\Pi(001)=2
$$

Similar calculations reveal that the interactions between activities $\mathrm{A}$ and $\mathrm{C}$ as well as between $\mathrm{B}$ and $\mathrm{C}$ are generically complementary. Now consider a single modification to the payoff structure: Assume that changing all three activities yields a benefit of four rather than six, i.e., $\Pi(111)=4$; changing all three activities is still more beneficial than changing any two, but less so than previously. With this single modification, all three interactions between $\mathrm{A}, \mathrm{B}$, and $\mathrm{C}$ become contextual. Consider, for instance, $\mathrm{A}$ and $\mathrm{B}$. When $\mathrm{C}$ is at $0, \mathrm{~A}$ and $\mathrm{B}$ are still complements, yet when $\mathrm{C}$ is at $1, \mathrm{~A}$ and $\mathrm{B}$ are now substitutes:

for $\mathrm{C}=0$ : payoffs are as given above for $\mathrm{C}=1$ :

A's marginal benefit is smaller at the higher level of B:

$$
1=\Pi(111)-\Pi(011)<\Pi(101)-\Pi(001)=2
$$

B's marginal benefit is smaller at the higher level of A:

$$
1=\Pi(111)-\Pi(101)<\Pi(011)-\Pi(001)=2
$$


The same relationships are found between $\mathrm{A}$ and $\mathrm{C}$ (both are complements if $\mathrm{B}=0$ and substitutes if $\mathrm{B}=1$ ) and between $\mathrm{B}$ and $\mathrm{C}$ (complements if $\mathrm{A}=0$ and substitutes if $\mathrm{A}=1$ ). Similar results are achieved for other modifications of the payoff structure (e.g., changing $\Pi(001)$ from one to three creates contextual interactions between $\mathrm{A}$ and $\mathrm{C}$, and $\mathrm{B}$ and $\mathrm{C}$, while retaining the generic complementarity between $\mathrm{A}$ and $\mathrm{B}$ ). While not every modification to the payoff structure eliminates the generic complementarity among A, B and C (e.g., increasing $\Pi(111)$ to seven leaves the generic complementarity intact), the strict conditions required by generic complementarity are easily violated, creating contextual interactions.

$<$ FIGURE 2 ABOUT HERE $>$

We can combine the distinction between generic and strategy-specific activities and between generic and contextual interactions to create a typology with four distinct activity/interaction combinations (see Figure 3). First, generic activities that display generic interactions represent industry-wide best practices. The optimal configuration of these activities is similar for all firms

within an industry. The interactions among these activities is similar for all firms as well. (This also encompasses the case in which activities are independent from each other, i.e., when interactions are zero for all firms).

Second, for firm-specific activities with generic interactions the value of particular configurations is strategy-specific and the optimal configuration depends on other strategic choices of the firm. The nature of the interactions among these activities, however, is similar across firms. For instance, investments in flexible manufacturing processes and frequency of design changes tend to be complementary in all firms. (The marginal benefit of being able to switch from one production run to the next is larger the higher the frequency of design changes, and vice versa.) The optimal configuration of these activities may differ across firms, since the 
benefit of flexible manufacturing coupled with frequent design changes is affected by strategic positioning, e.g., with respect to a firm's target customers (lead adopters vs. mass market).

The third case, industry-wide best practices with contextual interactions is rare. Only in the special case in which the contextuality of the interaction between two activities is entirely caused by the particular level of either activity, does the optimal configuration of these activities remain similar for all firms within an industry. ${ }^{5}$ Thus, in this case, the activities are still industry-wide best practices, yet display interactions that do not fulfill the strict complementarity assumptions, i.e., are contextual.

Fourth, for firm-specific activities with contextual interactions both the optimal configuration and the interactions among them are context-dependent. For examples of such sets of activities see the next section. It is important to note that firm-specific activities and contextual interactions go frequently hand in hand. If contextuality of the interaction between two activities is caused by a third activity, the optimal configuration of the activities is also influenced by this third activity. Thus, in this case, the contextual interaction between the activities causes the activities to become strategy-specific as well. ${ }^{6}$

\section{$<$ FIGURE 3 ABOUT HERE $>$}

\section{Illustrations of contextuality}

To explore the contextuality framework, we examine cases that illustrate contextuality in its various forms. First, violations of condition (1b) are described, i.e., contextuality that is caused by the level of the activities. Second, examples of violations of condition (1c) are explored, i.e., contextuality that is caused by other activity choices.

To illustrate a situation in which activities may be complementary only over certain ranges of their levels (violation of condition 1b), we continue with the example of Progressive 
Corporation. Progressive's quick response approach in the automobile insurance industry allows the company to lower total costs by reducing the frequency of litigation in serving high-risk customers. Let $\mathrm{T}=t_{1}+\ldots .+t_{n}$ be the total time between accident and issuing a check, i.e., the time required for the $n$ activities that lie between accident and the issuing of a check. Let $\mathrm{P}(\mathrm{T})$ be the net benefit function of having a response time T. Since shorter response times are beneficial for Progressive, $\mathrm{P}(\mathrm{T})$ is decreasing. Depending on the shape of $\mathrm{P}(\mathrm{T})$, investments in activities that shorten the total time to settlement are complementary, or not. Strict complementarity requires that $\mathrm{P}(\mathrm{T})$ is convex over the entire range of $\mathrm{T}$. While an argument can be made that $\mathrm{P}(\mathrm{T})$ may be convex within a certain range of $\mathrm{T}$, the convexity of $\mathrm{P}(\mathrm{T})$ is unlikely to hold over all possible levels of T. For instance, if it takes adjusters a relatively long time to settle claims (two weeks are not uncommon in the industry), a reduction in processing time by a few days is likely to go unnoticed with customers and creates no benefit for the insurance company (the investments are not complementary). If, however, the adjuster contacts the person within a day, the same reduction in processing time may have considerable benefit to the insurance company (both in terms of customer satisfaction and likelihood of involving a lawyer), as the insured party may respond positively to the noticeable reduction of total processing time. (In other words, the efficiency improvement is not swamped by large delays introduced by other parts of the settlement process.) Thus, the investment in one activity increases the marginal benefit of investing in the other activity - the activities are complementary. Finally, once both contact and processing time have been reduced to very short levels, the marginal benefit of decreasing one even further is likely to decline again, i.e., the investments cease being complementary.

This example also illustrates the empirical challenge of choosing the correct level at which the effects of complementarity are measured. Using the previous notation, a common question would be whether investments that reduce, say, $t_{1}$ and $t_{2}$ are complementary. Assume that an investment that reduces $t_{1}$ does not lead to a reduction in $t_{2}$, and vice versa. Thus, reductions in 
$\mathrm{T}$, through investments in $t_{l}$ and $t_{2}$, are strictly additive. In this case, if the efficiency of the process is measured by $\mathrm{T}$, no complementarity between the investments will be detected. At the same time, if $\mathrm{P}(\mathrm{T})$ is convex, we will detect a complementarity between the investments if $\mathrm{P}(\mathrm{T})$ is used to measure the effects.

\section{Contextuality due to other activity choices}

An even more interesting violation of the strict complementarity assumptions for company strategy is the case when interactions are affected by other choices (violation of condition (1c)). A firm's strategic positioning can transform the relationship between activities from one of complements to one of substitutes and vice versa. For example, in the automobile insurance setting, we described two different kinds of strategies with respect to response times. Given a strategy of postponing payments (up to the point when regulators step in), all activities that lead to a reduction in response times are substitutes. Any investment that reduces the time of one activity would lead to a decrease of the marginal benefit of speeding up another activity. However, with a strategy of decreasing total response time, these choices are complementary (at least over a certain range, as discussed in the previous section).

A more elaborate example of contextuality can be found in the mutual fund industry. In 1974, The Vanguard Group was formed, with Vanguard the umbrella brand for an array of individual mutual funds. In mutual funds, there are three main sets of activities: distribution (i.e., selling of fund shares), investment management, and administration. Originally, Vanguard, in common with other mutual fund providers, outsourced investment management to an investment management company, Wellington Management (WM). As was industry practice in the 1970s, Vanguard also distributed its funds using the same investment management company that managed the funds. Fund investors were charged a sales fee (load) of normally $8.5 \%$ to purchase fund shares. 
Vanguard differed from its competitors, however, in various ways. First, administrative services were not contracted out, but were provided at cost by The Vanguard Group itself. Second, The Vanguard Group was owned by the fund shareholders rather than by a separate set of shareholders. Its "mutual" organizational structure was unique in the industry. Lastly, Vanguard differed from its competitors in its overarching investment philosophy and the type of funds it promoted. John Bogle, Vanguard's charismatic CEO, believed that high and fairly predictable long-run investment returns could be achieved by incurring very low expenses and not attempting to outperform the market but to match it. Thus, Bogle introduced the industry's first index fund (based on the S\&P 500) in 1976 and increased Vanguard's offering of bond funds. In 1977, Vanguard decided to bring the distribution function in-house, and to market its funds as no-loads, i.e., not to charge any sales fees. In the following years, Vanguard also started to bring investment management for all bond funds in-house.

The interplay between the in-sourcing of investment management and the no-load, direct distribution system reveals the effect of contextuality. For Vanguard, bringing both investment management and distribution in-house was complementary, yet for other fund providers it was not. For the following discussion, see Figure 4.

$<$ FIGURE 4 ABOUT HERE $>$

The benefit of internalizing investment management was much greater after Vanguard had gained control over distribution. It would have been unwise for Vanguard to take away the (very lucrative) investment management business from WM, while still relying on WM to distribute its funds. WM would have been much less motivated to sell the funds. Thus, using the shorthand of Figure 4, moving from (1) to (2) was more beneficial at (4) than at (3). If in-sourcing investment management and direct distribution are complementary, the reverse is also true, i.e., changing from load-distribution to direct, no-load distribution is more valuable in the presence of internal 
investment management than with external investment management. (In other words, moving from (3) to (4) is more beneficial at (2) than at (1).) This reverse argument holds for Vanguard, but only in the context of its low-cost strategy, organizational structure, and fund portfolio. Internalization of investment management and distribution each decreased costs. By virtue of Vanguard's mutual structure these cost savings were passed through to the funds which therefore recorded higher net returns. It has been shown that fund inflows, in turn, respond in a convex manner to higher relative returns (Chevalier and Ellison, 1997; Sirri and Tufano, 1998). Thus, the benefit to Vanguard - in terms of asset growth — from decreasing its costs of investment management became larger when the costs of distribution were also reduced. Moreover, this effect was most pronounced for fund types for which small changes in expenses translated into large relative performance differences and were not swamped by large performance fluctuations. Thus, the complementary relationship arose strongly for the types of funds Vanguard was focusing on and for which it was in-sourcing the investment management, i.e., low-risk and index funds. Consistent with this contextual complementarity argument, Vanguard did not in-source the investment management for actively traded equity funds.

\section{Contextuality and activity interactions over time}

We have shown that the same set of activities may interact differently in different firms. The concept of contextuality can also be applied in a dynamic setting to a single firm. Two activities that were substitutes can become complements, and vice versa, as a firm's strategy and industry conditions change.

An example of how the relationship among activities can change over time can be found at Liz Claiborne, the largest fashion apparel manufacturer in the U.S. In the 1980s, Liz Claiborne focused on the apparel needs of the then rapidly growing professional women segment. Its collection provided high value to customers who looked to the brand to provide guidance about 
what constituted acceptable professional women's apparel and to assemble an array of items that were fashion coordinated. In its early years, Liz Claiborne was able to easily sell all of its output to its department store customers and required them to place binding orders at the beginning of the season.

Consider the subset of activities that influences the lead time between design and final delivery of the product. Each of these activities, from design itself to the management of contract manufacturers, involves configuration choices: e.g., conventional design vs. computeraided design, physical delivery of design and fabric samples to manufacturers vs. using on-line technology, etc.

When Liz Claiborne set fashion trends and could always sell its entire output, the benefits of decreasing its lead time were small. As long as Liz Claiborne was able to ship its merchandise at the beginning of the respective season, lead-time did not matter much. (For firms that were not able to "define" the market, shorter lead times were beneficial since they allowed the gathering of more information about the upcoming fashion trends.) Hence for Liz Claiborne, improvements in activities that led to a shortening of the total lead time were substitutes. More formally, let $\mathrm{T}=t_{1}+t_{2}+\ldots t_{n}$ be the total lead time, with $t_{1}, \ldots, t_{n}$, the time of the various activities from design to delivery. If there is no benefit in decreasing $\mathrm{T}$ (under the constraint that $\mathrm{T}$ is sufficiently small to guarantee shipment at the beginning of the season), then a decrease, for instance, in $t_{l}$, would lead to a reduction of the benefit of reducing $t_{2}$, i.e., investments that reduce $t_{1}$ and $t_{2}$ are substitutes. As the general quality of telecommunication increased over time, making communication with suppliers faster, the marginal benefit of investing in design technology (e.g., CAD systems) that would reduce lead time even further decreased for Liz Claiborne. Consistent with this relationship, Liz Claiborne invested very little in upgrading design technology (Henricks, 1995). 
In the 1990s, however, Liz Claiborne's competitive environment changed. First, the assurance of the Liz Claiborne brand became less important, leading to decreased consumer loyalty. With this change, shorter lead-times became valuable to Liz Claiborne, since shorter lead-times allowed it to wait longer and discern emerging fashion trends. Second, department stores experienced cash-flow problems as many chains had been involved in leveraged buy-outs or mergers involving high levels of debt. As a consequence, department stores sought to reduce inventories to free up cash, and increasingly demanded the delivery of merchandise in small lots and the option of reordering items during a season. To allow reordering efficiently, manufacturers had to move to at least partial production-to-order (Hammond, 1993). Productionto-order, in turn, was more effective with shorter overall lead times. Investments that sped up the design process were made more valuable by concurrent investments in information technology. For Liz Claiborne, upgrading design technology and upgrading information transmission technology had become complementary. (For the ensuing problems of current management in responding to this new interaction pattern, which required a wholesale restructuring of many activity choices, see Siggelkow (forthcoming)).

\section{Contextuality and Imitation}

The contextuality framework has important implications for management practice. Here, we focus on the effect of contextuality on the ease of imitation. The presence of systems of interactive activities generally increases the difficulty of competitor imitation (for formal models, see Porter and Rivkin, 1998; Rivkin, 2000). Briefly, systems of interactive activities are difficult to imitate because interactions among activities require that entire systems rather than individual activities be replicated. In other words, interactions cause the imitation-benefit relationship to be convex: if only a few elements of a system are copied, no benefit (or even negative benefits because of inconsistencies) is generated. Changing many activities simultaneously to duplicate 
entire systems is difficult. Empirical evidence of these considerations is provided by studies documenting the failure of U.S. automobile manufacturers to imitate the Japanese lean manufacturing system (e.g., Hayes and Jaikumar, 1988). By imitating only parts of the Japanese system, U.S. firms incurred large costs but failed to gain any benefits.

Strategy-specific activities are inherently more difficult and costly to imitate, because they are observable in fewer firms and often force imitators to suboptimize the configuration of their current activities (Porter, 1996). The contextuality of interactions further adds to the difficulty of imitating a competitor's activity system. In the presence of contextuality, managers who observe that two activities A and B are complementary for a competitor cannot conclude that the same two choices are complementary for their firm. Since contextuality means that the relationship between two activities depends on other activity choices, A and B may not be complements for the imitator unless the other contextually relevant activities are similar. Hence, benchmarking activities when competitors have made different choices (e.g., higher investment levels in certain processes) and imitating these choices may not lead to the desired performance improvements. It can potentially lead to performance declines.

Contextuality also implies that the relationship between existing activities can change as new activities are adopted. This means that incremental adaptation using established strategic heuristics or adjustment routines (Nelson and Winter, 1982) may fail. For instance, firms that imitate leading firms frequently cannot observe the entire set of choices the leader has undertaken. Hence, the imitator duplicates the observable choices and attempts to figure out the remaining set of choices for itself, hoping that its system of routines and traditional operating procedures will bring about optimal readjustments. Yet, if the nature of the relationship between existing activities has changed after the adoption of new activities, either no or even counterproductive adjustments will be made. What used to be good habits have turned into bad habits. 
Examples of this consequence of contextuality have been reported in the innovation literature (Henderson and Clark, 1990; Henderson, 1993). Incumbent firms have been found to experience severe difficulties in responding to "architectural" innovations that are characterized not by new parts of a system, but by new ways in which the parts of a system interact with each other. The interactions among the components of a product, or more generally, among activities of a firm, leave organizational imprints, such as who communicates with whom, what type of information is gathered and shared, and what heuristics are used to solve problems or to make investment decisions. If relevant interactions change, the existing organizational structures and processes that arose in the context of the old set of interactions can become very misleading.

To these issues, consider a firm such as The Gap that operates a distribution system linking warehouses and stores. Assume that the firm's current ordering system allows stores to order goods once a week. In this case, the benefit of increasing delivery frequency of ordered goods to, say, daily delivery, is very low. However, if the firm were to order daily, then the benefit of increasing the delivery frequency from once a week to daily is high. Conversely, the benefit of ordering daily is lower when the firm is delivering only once a week rather than once a day. Thus, ordering frequency and delivery frequency are complementary. But note that this complementarity is contextual: it only exists if the firm has relevant information for ordering on a daily basis. A point-of-sales (POS) system may generate this information. Thus, without a POS system, the complementary relationship does not exist. It is the presence of the POS system that makes the relationship complementary. ${ }^{7}$ Existing investment routines that were formed in the old regime (i.e., in the absence of a POS system), will not have incorporated a relationship between ordering and delivery frequency. With these old routines in place, the installation of the POS system (e.g., a salient feature of a competitor that was replicated) may not be accompanied by increased investment in ordering and distribution frequency. Moreover, even if the firm 
increased investment in one of these activities, the old routines would not lead to a self-adjusting increase in the investment of the other activity.

\section{Implications for large-sample empirical research}

The contextuality of both activity configurations and interactions poses significant challenges for empirical work, because identifying contextuality often requires an in-depth knowledge of the activity systems of each firm or "data point." While such in-depth knowledge is difficult to obtain for large samples, our framework nevertheless suggests new directions for large-sample research. In analyzing the benefits of adopting a bundle of production practices (say, A, B and C), assume that adopting the bundle yields a higher labor efficiency for the sample as a whole than adopting the practices separately. Our framework suggests the additional question whether the configuration is particularly beneficial (or detrimental) for specific strategies. By pooling across all observations, we only know that the bundle of practices is beneficial on average. However, it may be that A, B and C are beneficial (and/or mutually reinforcing) only for companies that produce standardized outputs, while they are detrimental (and/or mutually independent or even substitutes) for companies that produce highly customized outputs (or vice versa). By exploring potential sources of contextuality, we can deepen our understanding of the interaction phenomena.

Contextuality of interactions could be explored by testing whether interaction effects are constant over the entire sample. Interaction effects are frequently studied by including the product of two variables in a regression model. Thus, if the interaction between A and B is tested, the regression model would include a term such as $\beta^{*} \mathrm{~A}^{*} \mathrm{~B}$. Contextuality due to the level of activities, i.e., violation of condition (1b), could be tested by exploring whether $\beta$ is a function of the level of A and B. This may require splitting the sample into groups depending on their levels of A and B and testing whether the $\beta$ 's are different across the groups. Contextuality due 
to other activities, i.e., violation of condition (1c), could be tested by exploring whether $\beta$ is a function of other variables $\mathbf{C}$. Dividing the sample into subgroups using $\mathbf{C}$ and testing for differences of $\beta$ might be a first step to explore this type of contextuality.

Another avenue for empirical work is to examine a broader array of performance measures, including measures more tied to overall strategy. Most existing research on complementarities employs narrowly defined efficiency measures such as labor input per unit of output. These measures offer comparability across processes, but they may have different relevance for firms with different strategies. Ideally, a performance measure should incorporate both the cost and the price elements of the product, i.e., some form of margin or profit contribution measure. For instance, a firm that produces highly customized products may not want to adopt the bundle A, B and $\mathrm{C}$, if adoption of this bundle hampers the ability to customize products and thereby command higher prices. While a different optimal bundle might result in lower (labor) efficiency for firms producing standardized outputs, the price premium for the customized products can outweigh the efficiency loss. In this case, the firm is pursuing a differentiation strategy (Porter, 1980). A focus only on narrow measures of efficiency as performance measure implicitly suppresses strategy differences. This approach assumes that all firms will value the measure similarly, i.e., that all firms follow the same strategy. This neglects important dimensions of competition and can yield flawed interpretations of empirical results.

\section{Conclusion}

In recent years, the concept of fit among firm activities has found renewed interest. Current research has focused largely on universal best practices, i.e., on activity configurations that are beneficial across many firms and industries. The interactions examined have been largely restricted to complementarities defined in a narrow sense. The contextuality framework developed in this paper suggests the need to extend research in several directions. Activity 
configurations are often contingent on strategy. Moreover, the nature of interactions among activities is frequently contextual, i.e., driven by other choices a firm has made. In other words, interactions between activities are often endogenous to a firm's positioning (i.e., a function of its full set of activities) rather than being an inherent property of the activities themselves.

In addition to offering a richer understanding of the role that interactions play in creating and sustaining a competitive advantage, relaxing the complementarity conditions raises interesting new issues that have received little attention. For instance, when the relationship between activities changes from substitutes to complements without decision makers' knowledge, the performance consequences can be serious (Siggelkow, 2000).

Empirical support for the existence of strategy-specific interactions and for their contextuality is mainly derived so far from in-depth field-research. Future research in larger samples is needed. To capture the richness of the phenomenon, while still allowing for (limited) statistical power, new empirical research treading a middle ground between individual case studies and large-sample research may prove to be the most fruitful approach. Incorporating the possibility of contextual relationship in future research is certainly no small task, but to increase our understanding of competitive advantage through the interactions among activities, it is a necessary one. 
Figure 1. Generic Activities in a Performance Landscape

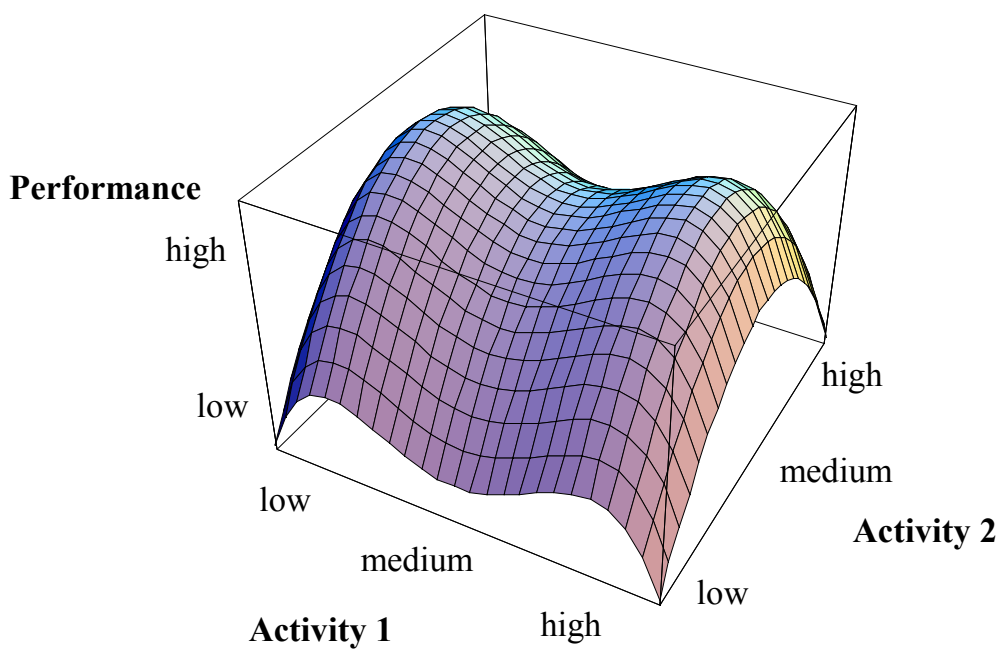

A medium level of Activity 2 is optimal regardless of how Activity 1 is configured. Hence, Activity 2 is generic. Even though Activity 2 is generic, two different positionings are still possible, with Activity 1 chosen at either a low or high level.

Figure 2. Generically complementary interactions

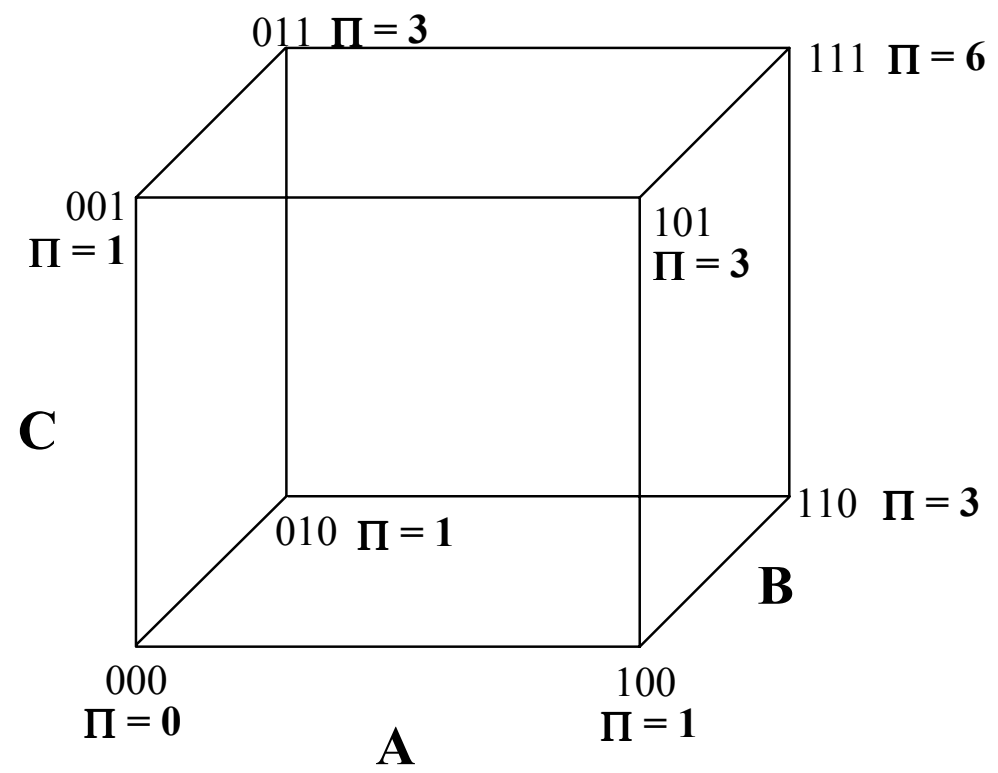

Each activity A, B, and C can be configured in two ways, 0 and 1 . Each vertex of the cube represents one of the eight different possible combinations. The payoff associated with each combination is given next to each vertex. 
Figure 3. Activity/Interaction Typology

\begin{tabular}{|c|c|c|}
\hline & $\begin{array}{c}\text { generic } \\
\text { activities }\end{array}$ & $\begin{array}{c}\text { strategy-specific } \\
\text { activities }\end{array}$ \\
\hline $\begin{array}{c}\text { generic } \\
\text { interactions }\end{array}$ & $\begin{array}{c}\text { industry-wide } \\
\text { best practices }\end{array}$ & $\begin{array}{c}\text { firm-specific } \\
\text { activities with } \\
\text { generic interactions }\end{array}$ \\
\hline $\begin{array}{c}\text { contextual } \\
\text { interactions }\end{array}$ & $\begin{array}{c}\text { industry-wide } \\
\text { best practices } \\
\text { with contextual } \\
\text { interactions }\end{array}$ & $\begin{array}{c}\text { firm-specific } \\
\text { activities with } \\
\text { contextual interactions }\end{array}$ \\
\hline
\end{tabular}

Figure 4. Contextuality within Vanguard's Activity System

\begin{tabular}{|cccc|}
$\begin{array}{c}\text { internal investment } \\
\text { management }\end{array}$ & (2) & $\begin{array}{c}\text { direct distribution } \\
\text { (no-load) }\end{array}$ & \\
$\begin{array}{c}\text { external investment } \\
\text { management }\end{array}$ & 1 & external distributor \\
(load) & & \\
\hline
\end{tabular}




\section{$\underline{\text { Appendix }}$}

This appendix provides a more general treatment of the theory of complements as introduced by Milgrom and Roberts (1990a) and further developed in subsequent work.

A lattice $(X, \geq)$ is a set $X$ with a partial order $\geq$ with the property that for any $x$ and $y$ in $X, X$ also contains a smallest element under the order that is larger than both $x$ and $y$ and a largest element that is smaller than both. Let $x \vee y$ denote the smallest element larger than $x$ and $y$, and $x \wedge y$ denote the largest element smaller than $x$ and $y$. A sublattice of a lattice $X$ is a subset $S$ of

$X$, if for any $x, y \in S,(x \wedge y) \in S$, and $(x \vee y) \in S$. Given a real-valued function $f$ on a lattice $X, f$ is called supermodular and its arguments are complements if and only if for any $x$ and $y$ in $X$, $f(x)-f(x \wedge y) \leq f(x \vee y)-f(y)$. With these definitions, the main comparative static result can be stated as follows: Let $f: X \times \Re \rightarrow \Re$ be a supermodular function and let $x^{*}(\theta)$ be the set of maximizers of $f(x, \theta)$ subject to $x \in S$. If $S$ is a sublattice, then $x^{*}(\theta)$ is monotone nondecreasing in $\theta$ (Milgrom, Roberts and Athey, 1996). In words, the (optimized) choice variables move up and down together, i.e., a change that favors increasing any one variable leads to increases in all the variables. Note, this result imposes relatively weak conditions on $f$. For instance, $f$ is not required to be concave or continuous. Moreover, it can be shown that the condition of supermodularity is the weakest condition on $f$ that is sufficient to yield the same comparative statics result (Milgrom, Roberts and Athey, 1996).

While the above result holds only for systems of complements (and thus has focused research on these systems), the theory can incorporate a limited amount of other relationships. First, if variable $y$ is a substitute to all other variables in the system, then variable $-y$ is a complement and the result above directly applies. This sign-switching trick does not work, however, if $y$ is not a substitute to all other variables. Second, the comparative static result with respect to the optimal choices of a set of complements $x_{1}, \ldots, x_{n}$ are retained if other disjoint sets of variables $y^{i}$ each affect only one $x_{i}$. The relationship among the variables $y^{i}$ is unrestricted. Formally, if the payoff can be written as $f\left(x_{1}, \ldots, x_{n}\right)+\Sigma g^{i}\left(x_{i}, y^{i}\right)$ for some disjoint sets of variables $y^{i}$ and $f$ is supermodular, then the function $f^{*}\left(x_{1}, \ldots, x_{n}\right) \equiv \sup _{\mathrm{y}} f\left(x_{1}, \ldots, x_{n}\right)+\Sigma g^{i}\left(x_{i}, y^{i}\right)$, obtained by maximizing out the $y^{i}$ variables, is supermodular as well (Milgrom and Roberts, 1995). 


\section{$\underline{\text { References }}$}

Abernathy, F. H., J. T. Dunlop, J. H. Hammond and D. Weil (1995). 'The information-integrated channel: A study of the U.S. apparel industry in transition', Brookings Papers:

Microeconomics, 7, pp. 175-246.

Antonelli, C., P. Petit and G. Tahar (1990). 'The diffusion of interdependent innovations in the textile industry', Structural Change and Economic Dynamics, 1, pp. 207-224.

Athey, S. and A. Schmutzler (1995). 'Product and process flexibility in an innovative environment', RAND Journal of Economics, 26, pp. 557-574.

Athey, S. and S. Stern (1998). 'An empirical framework for testing theories about complementarity in organizational design', Working paper \#6600, NBER, Cambridge, MA.

Bagwell, K. and G. Ramey (1994). 'Coordination economies, advertising, and search behavior in retail markets', American Economic Review, 84, pp. 498-517.

Brown, C., M. Reich and D. Stern (1993). 'Becoming a high-performance work organization: The role of security, employee involvement and training', International Journal of Human Resource Management, 4, pp. 247-275.

Caves, R. E. and P. Ghemawat (1992). 'Identifying mobility barriers', Strategic Management Journal, 13, pp. 1-12.

Caves, R. E. and M. E. Porter (1977). 'From entry barriers to mobility barriers', Quarterly Journal of Economics, 91, pp. 241-261.

Chandler, A. D., Jr. (1962). Strategy and Structure. MIT Press, Cambridge, MA.

Chevalier, J. and G. Ellison (1997). 'Risk taking by mutual funds as a response to incentives', Journal of Political Economy, 105, pp. 1167-1200.

Clark, T., H. and J. H. Hammond (1995). 'Channel transformation: Improving supply-chain performance by redesigning channel replenishment processes', Working paper \#95-093, Harvard Business School, Boston.

Cockburn, I. M., R. M. Henderson and S. Stern (1999). 'Balancing incentives: The tension between basic and applied research', Working paper 6882, National Bureau of Economic Research, Cambridge, MA.

Colombo, M. G. and R. Mosconi (1995). 'Complementarity and cumulative learning effects in the early diffusion of multiple technologies', Journal of Industrial Economics, 43, pp. 1348 .

Cool, K. and I. Dierickx (1993). 'Rivalry, strategic groups and firm profitability', Strategic Management Journal, 14, pp. 47-59.

Cool, K. and D. E. Schendel (1987). 'Strategic group formation and performance: The case of the U.S. pharmaceutical industry, 1963-1982’, Management Science, 33, pp. 1102-1124. 
Cool, K. and D. E. Schendel (1988). 'Performance differences among strategic group members', Strategic Management Journal, 9, pp. 207-223.

Cusumano, M. A. (1994). 'The limits of 'lean', Sloan Management Review, 35(Summer), pp. $27-32$.

Drazin, R. and A. H. Van de Ven (1985). 'Alternative forms of fit in contingency theory', Administrative Science Quarterly, 30, pp. 514-539.

Fiegenbaum, A. and H. Thomas (1995). 'Strategic groups as reference groups: Theory, modeling and empirical examination of industry and competitive strategy', Strategic Management Journal, 16, pp. 461-476.

Fierman, J. (1995). 'It's 2 a.m., let's go to work', Fortune, August 21, pp. 82.

Hambrick, D. C. (1984). 'Taxonomic approaches to studying strategy: Some conceptual and methodological issues', Journal of Management, 10, pp. 27-41.

Hammond, J. H. (1993). 'Quick response in retail/manufacturing channels'. In J. Hausman and R. Nolan (eds.), Globalization, Technology, and Competition. Harvard Business School Press, Boston, pp. 185-214.

Hatten, K. J. and M. L. Hatten (1987). 'Strategic groups, asymmetrical mobility barriers and contestability’, Strategic Management Journal, 8, pp. 329-342.

Hatten, K. J. and D. E. Schendel (1977). 'Heterogeneity within an industry: Firm conduct in the U.S. brewing industry, 1952-1971', Journal of Industrial Economics, 26, pp. 97-113.

Hayes, R. H. and R. Jaikumar (1988). 'Manufacturing's crisis: New technologies, obsolete organizations', Harvard Business Review, 66(September-October), pp. 77-85.

Henderson, R. M. (1993). 'Underinvestment and incompetence as responses to radical innovation: Evidence from the photolithographic alignment equipment industry', $R A N D$ Journal of Economics, 24, pp. 248-270.

Henderson, R. M. and K. B. Clark (1990). 'Architectural innovation: The reconfiguration of existing product technologies and the failure of established firms', Administrative Science Quarterly, 35, pp. 9-30.

Henricks, M. (1995). 'Making Liz first', Apparel Industry Magazine, 56(9), pp. 28.

Hitt, L. M. and E. Brynjolfsson (1997). 'Information technology and internal firm organization: An exploratory analysis', Journal of Management Information Systems, 14, pp. 81-101.

Holmström, B. and P. R. Milgrom (1994). 'The firm as an incentive system', American Economic Review, 84, pp. 972-991.

Hwang, M. Y. and D. Weil (1998). 'Production complementarities and the diffusion of modern manufacturing practices: Evidence from the U.S. apparel industry', Working paper, Pomona College and Boston University. 
Ichniowski, C. and K. Shaw (1999). 'The effects of human resource management systems on economic performance: An international comparison of U.S. and Japanese plants', Management Science, 45, pp. 704-721.

Ichniowski, C., K. Shaw and G. Prennushi (1997). 'The effects of human resource management practices on productivity: A study of steel finishing lines', American Economic Review, 87, pp. 291-313.

Jaikumar, R. (1989). 'Japanese flexible manufacturing systems', Japan and the World Economy, 1, pp. 113-143.

Kauffman, S. A. (1993). The Origins of Order: Self-Organization and Selection in Evolution. Oxford University Press, New York.

Khandwalla, P. N. (1973). 'Viable and effective organizational designs of firms', Academy of Management Journal, 16, pp. 481-495.

Learned, E. P., C. R. Christensen, K. R. Andrews and W. D. Guth (1961). Business Policy: Text and Cases. Irwin, Homewood.

Levinthal, D. A. (1997). 'Adaptation on rugged landscapes', Management Science, 43, pp. 934950.

MacDuffie, J. P. (1995). 'Human resource bundles and manufacturing performance:

Organizational logic and flexible production systems in the world automobile industry', Industrial and Labor Relations Review, 48, pp. 197-221.

MacDuffie, J. P. and J. F. Krafcik (1992). 'Integrating technology and human resources for highperformance manufacturing: Evidence from the international auto industry'. In T. Kochan and M. Useem (eds.), Transforming Organizations. Oxford University Press, New York, pp. 209-226.

McGee, J. and H. Thomas (1986). 'Strategic groups: Theory, research and taxonomy', Strategic Management Journal, 7, pp. 141-160.

Milgrom, P. R., Y. Qian and J. Roberts (1991). 'Complementarities, momentum, and the evolution of modern manufacturing', American Economic Review, 81, pp. 84-88.

Milgrom, P. R. and J. Roberts (1990a). 'The economics of modern manufacturing: Technology, strategy, and organization', American Economic Review, 80, pp. 511-528.

Milgrom, P. R. and J. Roberts (1990b). 'Rationalizability, learning, and equilibrium in games with strategic complementarities', Econometrica, 58, pp. 1255-1277.

Milgrom, P. R. and J. Roberts (1995). 'Complementarities and fit: Strategy, structure, and organizational change in manufacturing', Journal of Accounting and Economics, 19, pp. 179-208.

Milgrom, P. R. and J. Roberts (1996). 'The LeChatelier principle', American Economic Review, 86, pp. 173-179. 
Milgrom, P. R., J. Roberts and S. Athey (1996). 'Monotone methods for comparative statics analysis', mimeo, Stanford University.

Milgrom, P. R. and C. Shannon (1994). 'Monotone comparative statics', Econometrica, 62, pp. $157-180$.

Miller, D. (1981). 'Toward a new contingency perspective: The search for organizational gestalts', Journal of Management Studies, 18, pp. 1-26.

Miller, D. (1986). 'Configurations of strategy and structure: Towards a synthesis', Strategic Management Journal, 7, pp. 233-249.

Miller, D. and P. H. Friesen (1978). 'Archetypes of strategy formulation', Management Science, 24, pp. 921-933.

Miller, D. and P. H. Friesen (1984). Organizations: A Quantum View. Prentice Hall, Englewood Cliffs, NJ.

Mintzberg, H. (1979). The Structuring of Organizations. Prentice Hall, Englewood Cliffs, NJ.

Nelson, R. R. and S. G. Winter, Jr. (1982). An Evolutionary Theory of Economic Change. Harvard University Press, Cambridge, MA.

Nemetz, P. and L. W. Fry (1988). 'Flexible manufacturing organizations: Implications for strategy formulation and organizations design', Academy of Management Review, 13, pp. $626-638$.

Oster, S. (1982). 'Intra-industry structure and the ease of strategic change', Review of Economics and Statistics, 64, pp. 376-383.

Parthasarthy, R. and S. P. Sethi (1992). 'The impact on flexible automation on business strategy and organizational structure', Academy of Management Review, 17, pp. 86-111.

Parthasarthy, R. and S. P. Sethi (1993). 'Relating strategy and structure to flexible automation: A test of fit and performance implications', Strategic Management Journal, 14, pp. 529-549.

Porter, M. E. (1976). Interbrand Choice, Strategy, and Bilateral Market Power. Harvard University Press, Cambridge, MA.

Porter, M. E. (1979). 'The structure within industries and companies performance', Review of Economics and Statistics, 61, pp. 214-227.

Porter, M. E. (1980). Competitive Strategy. Free Press, New York.

Porter, M. E. (1985). Competitive Advantage. Free Press, New York.

Porter, M. E. (1996). 'What is strategy?', Harvard Business Review, 74(6), pp. 61-78.

Porter, M. E. and J. W. Rivkin (1998). 'Activity systems as barriers to imitation', Working paper no. 98-066, Harvard Business School, Boston, MA. 
Prat, A. (1996). 'Shared knowledge vs. diversified knowledge in teams', Journal of the Japanese and International Economies, 10, pp. 181-195.

Rivkin, J. W. (2000). 'Imitation of complex strategies', Management Science, 46, pp. 824-844.

Schaefer, S. (1999). 'Product design partitions with complementary components', Journal of Economic Behavior and Organization, 38, pp. 311-330.

Siggelkow, N. (2000). 'Misperceiving interactions: Organizational consequences', working paper, Wharton School, Philadelphia.

Siggelkow, N. (forthcoming). 'Change in the presence of fit: The rise, the fall, and the renascence of Liz Claiborne', Academy of Management Journal.

Sirri, E. and P. Tufano (1998). 'Costly search and mutual fund flows', Journal of Finance, 53, pp. 1589-1622.

Stalk, G. and A. M. Webber (1993). 'Japan's dark side of time', Harvard Business Review, 71(July-August), pp. 93-102.

Thomas, H. and V. Venkatraman (1988). 'Research on strategic groups: Progress and prognosis', Journal of Management Studies, 25, pp. 537-555.

Tirole, J. (1988). The Theory of Industrial Organization. MIT Press, Cambridge, MA.

Topkis, D. M. (1978). 'Minimizing a submodular function on a lattice', Operations Research, 26, pp. 305-321.

Whittington, R., A. Pettigrew, S. Peck, E. Fenton and M. Conyon (1999). 'Change and complementarities in the new competitive landscape: A European panel study, 19921996', Organization Science, 10, pp. 583-600. 


\section{$\underline{\text { Footnotes }}$}

${ }^{1}$ An activity is a discrete economic process within the firm such as delivering finished products or training employees that can be configured in a variety of ways.

${ }^{2}$ A performance landscape is a mapping from sets of activity configurations onto performance values.

${ }^{3}$ A study conducted by the independent Insurance Research Council showed that after paying their doctor and lawyer fees, policyholders who hire an attorney end up with less compensation than those who do not involve a lawyer (Fierman, 1995).

${ }^{4}$ The complementarity framework can incorporate a limited amount of substitutes (see the Appendix).

${ }^{5}$ Only in the special case in which multiple equilibria with equal payoffs exist is the optimal configuration of $\mathrm{A}$ and $\mathrm{B}$ not unique.

${ }^{6}$ For instance, let the benefit of activities A and B, given that the firm has made a third activity choice $\mathrm{C}$, be given by: $\mathrm{V}=\mathrm{A}+\mathrm{B}+\mathrm{C}^{*} \mathrm{~A}^{*} \mathrm{~B}$. Note, $\mathrm{C}$ affects how the level of one activity affects the marginal benefit of the other activity, i.e., $\mathrm{C}$ affects the interaction between $\mathrm{A}$ and $\mathrm{B}$, implying that $\mathrm{A}$ and $\mathrm{B}$ have a contextual interaction effect. By affecting the interaction between A and B, C also affects the benefit of different levels of A and B. Hence, A and B's optimal configurations are contextually determined as well-A and B are strategy-specific activities. ${ }^{7}$ In the case of The Gap, the benefits of its investments in logistics and information technology, which allowed frequent restocking, were further strengthened by its overall positioning on basic apparel, its strategy of frequent product changes, and its information technology that allowed quick data exchange between designers and manufacturers. 